\title{
Trambolho: Interface híbrida para negociação espacial de grupos remotos
} Trambolho: Hybrid interface for remote spatial negotiation

\author{
Estevam Quintino \\ Universidade Federal de Minas Gerais, Brasil \\ estevamgomes@gmail.com
}

\begin{abstract}
The dialogue between people from different social groups (class, gender, race or sexual orientation) could help develop a sense of empathy, reduce discrimination and catalyze socio-spatial transformations. However, the space usually acts segregating these groups or suggesting how they should behave. Architects, usually unconsciously, reinforce this through their practice, labeling otherwise abstract spaces to determine users behaviour and so reproducing social norms. The aim of this article is to investigate how space shapes human interaction and to introduce Trambolho, an interface that is not attached to any previous meaning, which people can use to negotiate and build a shared space.
\end{abstract}

Keywords: Interface; Non-verbal communication; Interaction; Telecommunication; Physical computing.

\section{Introdução}

Este artigo apresenta o Trabalho de Conclusão de Curso do autor no curso de graduação em Arquitetura e Urbanismo diurno da Universidade Federal de Minas Gerais, finalizado em dezembro de 2014. O trabalho tem por pressuposto a importância da interação entre pessoas de grupos sociais distintos para desconstruir preconceitos, desenvolver um sentimento de empatia e promover a cooperação, propiciando eventualmente uma transformação sócioespacial.

Inicialmente, o projeto pretendia abordar a aplicação de novas tecnologias no ambiente de ensino/aprendizagem tradicional em escolas de ensino médio, como meio de iniciar discussões sócio-espaciais através da conexão remota de pessoas de dois grupos sociais distintos. Foram duas as motivações principais que instigaram o desenvolvimento desse projeto. A primeira foi uma experiência pessoal, em que o professor de Ensino Religioso, visando proporcionar a interação entre jovens de grupos sociais distintos, promoveu dois encontros entre os alunos de classe média e alta de uma escola particular, com alunos de baixa renda de uma escola pública na periferia. Cada encontro ocorreu em uma escola e, apesar de gerarem desconforto e evidenciarem diferenças, não foram suficientes para que os alunos construíssem questionamentos sobre os processos que produzem a desigualdade e a pobreza, e nem mesmo refletir sobre sua contribuição individual para a manutenção desses processos. A segunda motivação veio dos "rolezinhos", uma série de eventos que ocorreram no Brasil no início de 2014. Estes eventos foram encontros de jovens da periferia, marcados pelas redes socais, em shopping centers e parques públicos. Os eventos resultaram em um grande desconforto para os usuais frequentadores dos locais e uma série de conflitos com a polícia e com a segurança particular dos shoppings centers.
Esses eventos estimularam uma investigação mais aprofundada para entender o papel do espaço no encontro e na interação entre pessoas de classes sociais diferentes, tanto em situações cotidianas, como relações entre patrão e empregado, quanto em situações extraordinárias, como os "rolezinhos". Dois autores foram fundamentais na formulação do papel do espaço e dos arquitetos na produção do espaço. Primeiro Lefebvre (1976), que trata da sobrevivência do capitalismo por meio da reprodução das relações sociais de produção. Para Lefebvre o espaço é o principal agente de tal reprodução e, portanto, fundamental na manutenção das desigualdades advindas com o capitalismo. Já Woods (1996), fala do papel dos arquitetos como intermediários entre as instituições e o usuário, e como eles determinam a forma e os usos do espaço para que os usuários permaneçam sob controle. Quando as determinações espaciais são questionadas os usuários normalmente são reprimidos. Dessa forma, o arquiteto que não atua contra o poder hegemônico, contribui para a reprodução das relações de produção capitalistas.

A partir dessas críticas ao papel do espaço e do arquiteto foi retomada a proposta de encontro entre pessoas de classes sociais distintas. Inicialmente, o foco era conectar duas escolas mas, como o espaço da escola tradicional é construído para estimular a reprodução das relações de poder (Foucault, 1987), mostrou-se necessário desenvolver um ambiente que pudesse receber o encontro entre os alunos e proporcionar uma interação horizontal. Para contornar a segregação espacial, foi proposto o uso de dispositivos de telecomunicação disponíveis e outros aparatos desenvolvidos em conjunto com os alunos. Após entrar em contato com escolas frequentadas por jovens de diferentes classes sociais, ficou clara a dificuldade de introduzir a discussão sobre a desigualdade social, principalmente nas escolas de classe média e alta. Os comentários eram os mais diversos, na maioria das vezes tentando alterar o projeto para amenizar o incômodo da discussão sócio-espacial. Diante das restrições das escolas, 
a pesquisa se voltou para a criação de uma interface não específica, que pudesse ser usada para conectar contextos distintos, como dois laboratórios de pesquisa, e possibilitar a interação horizontal entre as pessoas sem prescrever as ações.

Um dos principais focos passou a ser a discussão da telecomunicação, chamada aqui de comunicação no ciberespaço. Embora pessoas geograficamente distantes possam se comunicar no ciberespaço, ele apresenta uma série de limitações em relação à comunicação presencial. Além disso, como argumenta Massey (2006), a ideia de uma sociedade globalizada na qual a tecnologia anula as distâncias está se tornando um mito, pois, tal globalização, depende de quem você é e onde você está. Isso mostra que tanto a questão geográfica quanto a econômica são limites cruciais ao ciberespaço. No caso brasileiro, por exemplo, o IBGE (2015) aponta uma correlação: quanto maior renda per capta do grupo, maior o número de pessoas com acesso à internet. Outro caso, relatado por Barba et al. (2014), mostra que pequenos municípios do estado de Oaxaca, no México, tiveram dificuldades para se conectarem ao ciberespaço. As empresas de telecomunicação se recusaram a instalar a infraestrutura necessária no local pois a baixa densidade populacional e a distância de grandes centros urbanos reduziam a lucratividade do serviço.

Uma forma de tentar superar as limitações do espaço físico e do ciberespaço é a produção de interfaces híbridas. Levantamos alguns experimentos que apontam nessa direção (Quintino e Baltazar, 2014) cujas características informaram a produção de uma interface que espacializa a telecomunicação, ampliando a sensação de presença e pertencimento, e explora a comunicação não-verbal, criando um ambiente que possibilita a interação sem reproduzir de antemão as relações opressoras. Para o desenvolvimento de tal interface foi crucial avançar o entendimento do encontro e da interação no espaço físico e no ciberespaço, chegando ao espaço híbrido como alternativa viável.

\section{Encontro e interação no espaço físico}

As grandes cidades brasileiras são marcadas pela segregação espacial. Caldeira (2014) explica que a consolidação das periferias manteve as classes sociais fisicamente separadas, garantindo uma distância entre espaços de residência e consumo. Tal separação está diretamente ligada ao modo de produção capitalista que organiza as relações sociais, o espaço e o tempo (Lefebvre, 2000).

Apesar disso, o encontro entre pessoas de diferentes classes sociais ocorre diariamente. Porém, normalmente estão relacionados à prestação de serviços como, por exemplo, trabalhos domésticos ou na construção civil, e ocorrem em locais ocupados por segmentos de renda média e alta. Já as pessoas que pertencem às classes média e alta raramente frequentam áreas da cidade ocupadas por segmentos sociais de baixa renda (Lacerda e Bernardino, 2014, p. 205). Há um paralelo entre a mobilidade urbana atual e a circulação existente entre a casa grande e a senzala, observada no período escravocrata brasileiro, como colocado por Lacerda e Bernardino (2014, p. 205): "enquanto os escravos, sobretudo as mulheres, se deslocavam, embora não livremente, para exercer atividades domésticas na casa grande, os integrantes da família senhorial não frequentavam a senzala".

Essas relações cotidianas entre patrão e empregado, garçom e cliente, morador e porteiro, reproduzem a organização hierárquica e são marcadas por uma forma de opressão inconsciente, onde uma pessoa está subordinada à outra por questões culturais, sociais ou econômicas. O espaço físico manifesta essas hierarquias e prescreve as interações de diversas maneiras como, por exemplo, na separação entre as áreas de circulação e convivência de moradores e funcionários de um condomínio:

Quando a presença de pessoas de diferentes classes sociais coincidia, sempre foi possível criar sistemas perversos para regular encontros e garantir separações, sendo um dos mais cruéis deles o que duplicava e separava as áreas de circulação em edifícios entre a "social" e a "de serviço". (Caldeira, 2014, p. 18)

Outro exemplo de opressão inconsciente são relações missionárias ou assistencialistas que, embora busquem reduzir a desigualdade e a miséria, reforçam a relação de dependência, contribuindo para a manutenção do status quo. Como colocado por Demo (1998), para combater a pobreza, é necessário que o pobre se torne protagonista, não apenas beneficiário. Essa forma de opressão pode ser ilustrada pela experiência pessoal de um dos autores relatada na introdução. $O$ encontro entre os alunos de classe média e alta de uma escola particular com os alunos de uma escola pública na periferia gerou desconforto, evidenciou as diferenças sociais e sensibilizou os alunos de escola particular em relação à precariedade das condições dos alunos da escola pública. Porém, ao invés de refletirem sobre os processos que produzem a desigualdade e a pobreza, e sua contribuição individual para a manutenção desses processos, o encontro apenas alimentou o ideário assistencialista dos alunos da escola particular.

Já a opressão deliberada ocorre quando os acordos sociais e espaciais são questionados, como no caso dos "rolezinhos". Como explicado por Abreu (2015), estes eventos, organizados nas redes sociais, foram encontros de centenas de jovens da periferia em shopping centers, em sua maioria periféricos, e parques públicos. A presença desses jovens, que buscavam um espaço seguro para se encontrar, perturbou a organização e as interações prescritas pelo espaço (grupos pequenos de pessoas que frequentam o shopping para consumir), provocando um grande desconforto nos lojistas e na administração do shopping, que não sabiam como agir. Baseado em preconceitos, os lojistas acionaram a segurança particular do shopping e, em alguns casos a polícia, para conter a entrada ou expulsar os jovens. Apesar do medo de vandalismo e assaltos nos primeiros 
eventos, não foi registrada nenhuma queixa de roubo por parte das lojas. Ainda assim os responsáveis pelos shoppings recorreram à justiça e conseguiram obter autorização para proibir a entrada de jovens menores desacompanhados. Por um lado, eventos como os "rolezinhos" promovem inconscientemente a contestação das autoridades constituídas e modos de regulação e separação preexistentes no cotidiano. Por outro lado, a resposta a tais eventos, seja dos lojistas, seja dos frequentadores, seja das autoridades, é uma opressão consciente, embora pouco refletida, no intuito de não deixar abalar as bases da cidade estruturada para segregar e reproduzir desigualdades (Caldeira, 2014).

A interação assimétrica, principalmente quando se desdobra em conflito, exalta os contrastes sociais, mas coloca os envolvidos em posições defensivas e fechados ao diálogo, dificultando a reflexão e a discussão sobre os problemas sócio-espaciais. A opressão mantém o preconceito oculto e não leva nenhum dos lados a questionar seu papel na manutenção do sistema que produz a desigualdade e a miséria.

Como observado nos exemplos, o espaço é fundamental para o processo de interação social, podendo ou não contribuir para a reprodução das relações assimétricas. Woods (1996) afirma que projetar um espaço é um meio de controlar o comportamento humano. Assim, para as instituições sociais, a função do arquiteto é rotular espaços que antes eram abstratos e sem sentido, determinando suas funções e indicando aos usuários como devem se comportar. Para Woods (1996), a cidade pode ser entendida como uma rede de espaços projetados que prescrevem as interações sociais, os pensamentos e, se possível, até os sentimentos dos indivíduos. Os arquitetos, por sua vez, são programados por outras instituições políticas, econômicas e sociais.

Para possibilitar interações horizontais e ampliar a autonomia dos indivíduos, Woods (1996) sugere a criação de freespaces, zonas onde a interação entre os usuários não é pré-estabelecida. Alguns espaços urbanos, como praças e parques, não se enquadram como freespaces, mas por suas funções serem definidas com maior flexibilidade, determinam menos as interações das pessoas entre elas e com os espaços. No entanto, nem sempre pessoas de classes sociais diferentes frequentam esses espaços, já que o acesso está normalmente condicionado à proximidade geográfica. Algumas exceções ocorrem, seja pela centralidade dos parques ou devido à ocupação informal (favelas) de espaços em áreas centrais da cidade ou de fronteira com bairros de classe média e alta. Tais ocupações acabam proporcionando a aproximação física de pessoas de classes sociais distintas, com reações diferentes em cada contexto.

O Parque Municipal de Belo Horizonte, por exemplo, é um parque central onde apropriações não usuais por grupos de classe baixa foram reprimidas. Durante "rolezinhos" no parque, os jovens, embora libertos dos olhares repressores dos clientes e seguranças dos shoppings, eram vigiados à distância por guardas municipais e, em algumas ocasiões, revistados. Eventualmente apareciam representantes do Juizado da Infância e da Juventude e solicitavam que alguns jovens deixassem o parque, sob pretexto de preservar a integridade física e psicológica da criança e do adolescente (Abreu, 2015).

O Parque da Barragem Santa Lúcia, também em Belo Horizonte, foi construído em um espaço residual entre a favela do Morro do Papagaio e os bairros de classe média São Bento, Vila Paris, Santa Lúcia e Santo Antônio. Há uma enorme diferença econômica entre os moradores desses espaços, a renda familiar dos moradores do morro é de até dois salários mínimos, enquanto a renda familiar dos moradores dos bairros varia entre 26 e 67,3 salários mínimos (Lansky, 2012). O estudo realizado por Lansky (2012) relatou alguns momentos onde há interação entre pessoas de classes sociais diferentes. Um dos momentos acontece nas feiras semanais onde, em geral, os moradores do Morro são funcionários e os moradores do bairro consumidores. Outro exemplo é o uso compartilhado dos aparelhos de ginástica por pessoas de diferentes classes sociais, que revezam, conversam e interagem nos intervalos. O último exemplo é o Clube de Trocas, espaço da praça em torno da banca que diversas pessoas frequentam para trocar figurinhas adesivas. Esses encontros contam com a presença de pessoas de várias idades e origens mas, como o jogo dependia de um investimento financeiro, os jovens do Morro só podiam participar mediante a doação de figurinhas de alguém que havia completado o álbum. Para os jovens e adultos ricos o jogo tinha um fim em si mesmo enquanto para alguns jovens do Morro o objetivo era vender as figurinhas e conseguir algum dinheiro.

Ainda que o parque seja por excelência um espaço cuja função é aberta e menos determinada que a maioria dos espaço funcionais da cidade, possibilitando também interações horizontais, as relações que ocorrem tendem a se ser assimétricas. Minha hipótese é que isso se deve à leitura usual (pré conceito) que todos fazemos do outro (e dos outros grupos). Tal leitura é fundamentalmente baseada na comunicação visual, auditiva e verbal. Dificilmente conseguiremos nos livrar de tal comunicação no espaço físico. No entanto, mudando as formas de comunicação, é possível começar a investigar possibilidades de encontros genuinamente horizontais.

\section{Encontro e interação no ciberespaço}

Com o desenvolvimento dos meios de comunicação, a interação social deixou de se limitar ao espaço físico, ocorrendo também no ciberespaço. Embora os primeiros indícios de telecomunicação remontem há milhares de anos atrás, a interação remota desenvolveu-se apenas com a produção e a transmissão da eletricidade. Como explicado por Quintino e Baltazar (2014), em menos de dois séculos, os dispositivos de telecomunicação evoluíram do telégrafo, um simples aparelho que reduzia a riqueza da comunicação presencial a mensagens verbais, para dispositivos de telepresença que possibilitavam o uso da paralinguagem 
(e.g. uso da voz, entonação, ritmo) e da kinesia (e.g. dos gestos e expressões faciais). No entanto, as formas de telecomunicação mais difundidas, como mensagens de texto, telefone e videoconferência, ainda privilegiam a comunicação visual e verbal, o que dificulta o desenvolvimento de um sentimento de empatia entre os usuários.

Pesquisas sobre telepresença investigam meios para tornar a experiência de comunicação mais imersiva, ampliando a sensação de presença e pertencimento, e criando um "lugar" para o encontro. Para isso utilizam a atuação remota (e.g. robôs teleoperados), a transmissão em tempo real de imagens estereoscópicas e a criação de ambientes de imersão (e.g. Cave Automatic Virtual Environment). No entanto, esses ambientes não passam de pobres imitações da realidade onde a presença não é explorada além das limitações do espaço físico.

A evolução tecnológica ampliou as possibilidades de interação entre pessoas geograficamente distantes e tornou mais democrática a produção e o acesso à informação. No entanto, o ciberespaço também é produto do trabalho humano e, por isso, manifesta as desigualdade sociais e interfere na interação entre as pessoas. Além disso, o acesso à rede ainda é não é universal. Segundo os dados apresentados pelo IBGE (2015), é possível estabelecer uma correlação entre a o rendimento mensal domiciliar per capita e o acesso à internet: "em 2013 , o maior percentual $(89,9 \%)$ (de pessoas com acesso à internet) foi observado na classe de mais de 10 salários mínimos, enquanto o menor $(23,9 \%)$, na classe sem rendimento a $1 / 4$ do salário mínimo" (IBGE, 2015, p. 42).

O acesso a esse espaço também está atrelado ao espaço físico já que as redes de telecomunicação não estão homogeneamente distribuídas pelo mundo. Cidades pequenas ou distantes de grandes centros urbanos permanecem digitalmente desconectas, pois não atendem aos desejos econômicos das empresas de telecomunicação. Um exemplo é o município de Talea de Castro, no estado de Oaxaca, no México (Barba et al., 2014). As autoridades locais solicitaram às empresas de telecomunicação que instalassem a infraestrutura necessária para que os habitantes pudessem conectar seus aparelhos celulares à rede telefônica. No entanto, devido à pequena população do município, as empresas se recusaram, já que o investimento não traria o retorno financeiro desejado. Alguns países contornam a questão econômica exigindo legalmente que as empresas construam redes em áreas rurais, independente de quantas pessoas contratem o serviço, mas no México esse não é o caso.

Posto isso, mesmo que pessoas de classes sociais diferentes tenham acesso ao ciberespaço, o encontro depende do compartilhamento de interesses comuns. Interesses são construções sociais e refletem o grupo do qual a pessoa faz parte. Dessa maneira, o espaço digital reproduz parcialmente a segregação do mundo físico e, embora possibilite o encontro de pessoas distantes, elas não necessariamente fazem parte de grupos sociais diferentes. A segregação ainda é fortalecida por filtros criados por plataformas de busca ou redes sociais que entregam aos usuários apenas aquilo que corresponde ao perfil traçado pela empresa. Ainda assim a internet apresenta um grande potencial para a telecomunicação e a interação remota não verbal (mesmo que isso seja ainda exceção).

\section{O espaço híbrido como alternativa}

Uma alternativa à comunicação presencial e aos meios de telecomunicação existentes são as interfaces híbridas que buscam explorar a comunicação remota indireta do ponto de vista visual e não verbal. Alguns experimentos levantados por Quintino e Baltazar (2014) foram o Huggy Pijama, o DiDah-Dit e o Long Distance Voodoo.

O Huggy Pijama (Teh, 2008) busca transmitir remotamente a sensação de um abraço por meio de dispositivos hápticos. No entanto a comunicação é essencialmente unidirecional, impossibilitando um diálogo entre os usuários. Além disso, a interação possível é previsível, reduzindo o potencial de uma interação lúdica. O Di-Dah-Dit (VISNIJC, 2014) é um jogo telepresencial que, apesar do output predominantemente visual, possibilita uma atuação remota de fato, e o aspecto lúdico da interação cria uma experiência envolvente e comunicativa promovida pela negociação na ação (não verbal), além da abertura da interface que possibilita que os jogadores brinquem além da sua programação inicial.

O Long Distance Voodoo (Baltazar et al., 2014) consiste em uma boneca com sensores de pressão localizados na cabeça, nos dois braços e nas duas pernas e um vestível com motores e LEDs localizados em lugares análogos aos sensores da boneca. A boneca foi dependurada em frente à um café em Berlim e o vestível usado por um dançarino em uma praça em Belo Horizonte. Quando um participante em Berlim tocava na boneca um sinal era enviado para o vestível em Belo Horizonte vibrando o motor correspondente e estimulando um movimento do dançarino. Apesar de algumas dificuldades relatadas, a interface tátil explorou 0 sentimento de presença além da representação já que as pessoas estabeleceram uma conexão corporal através da atuação remota. A conexão disparou uma comunicação espacializada quando as pessoas gradualmente descobriam que poderiam tocar remotamente o dançarino, iniciando uma interação mais durável e significativa, já que o dançarino participava da conversa reagindo ao toque remoto $\mathrm{e}$ influenciando o resto do grupo, reverberando o estímulo recebido.

Para avançar a investigação sobre meios de telecomunicação não-verbal em tempo real, e experimentar um espaço alternativo para interação, foi desenvolvido a interface híbrida Trambolho. A interface consiste em duas estruturas autoportantes onde podem ser plugados sensores e atuadores que são combinados livremente pelos usuários. Cada estrutura é montada em um espaço e usa a internet para enviar dados de um ambiente ao outro em tempo real. Por ser autoportante e articulada, a estrutura tem flexibilidade para se adaptar e transformar os espaços, requalificando o ambiente onde ela se instala. Se montada em espaços ocupados anteriormente por grupos sociais 
diferentes, a interface pode proporcionar o encontro entre essas pessoas mesmo que não compartilhem o mesmo interesse ou que estejam separadas geograficamente. contínuo os usuários podem eventualmente desenvolver significados para essas ações. E, se levado ao limite, os usuários podem significar tais ações de forma colaborativa,

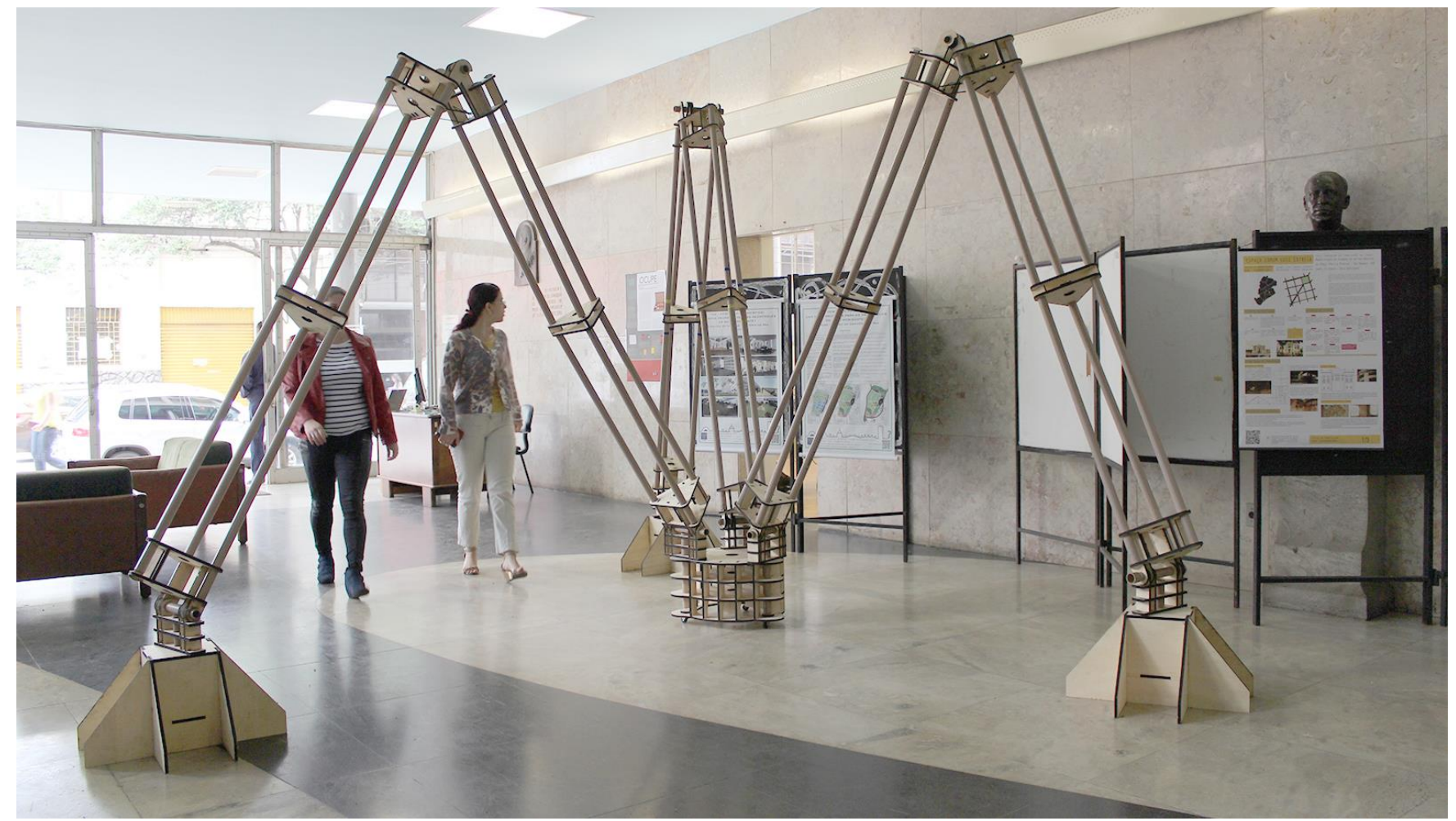

Figura 1: Vista da estrutura da interface sem sensores e atuadores acoplados.

A interface, por ser espacializada, possibilita uma comunicação mais imersiva, corporal e intuitiva, facilitando que pessoas sem conhecimento prévio possam manipulá-la. A telecomunicação se baseia em experiências sensoriais não verbais e não figurativas. Essas trocas de sensações, frequentes na comunicação presencial, mas pouco exploradas na telecomunicação, estimulam os usuários a se comunicarem de maneira mais espontânea, reduzindo a possibilidade de reprodução das relações hierárquicas e opressivas. Para isso o dispositivo dispõe de novos elementos para comunicação: sensores que captam giro, movimento, presença, proximidade, temperatura, umidade, direção, pressão e contato; conectados a atuadores que produzem correntes de ar, rotação, movimento, luz e som. As sensações produzidas não estão atreladas a significados previamente definidos nem representam outros objetos ou sentimentos, possibilitando aos usuários se apropriarem desses elementos e negociarem o seu significado.

$\mathrm{Na}$ linguagem verbal, por exemplo, cada palavra está atrelada a um significado, ou seja, representa algo, como a palavra cadeira representa um objeto ou a palavra amor representa um sentimento. A interface, por outro lado, conecta sensores e atuadores entre os ambientes. Sendo assim é possível que, ao mover uma alavanca em um espaço o usuário ative um ventilador no outro espaço. Dessa forma o usuário produz uma corrente de ar no ambiente remoto e, diferente da palavra cadeira, a corrente de ar não representa algo, mas provoca uma sensação. A partir do uso sem nenhum tipo de prescrição.

A comunicação não verbal proporcionada pode ser utilizada de maneira autônoma ou pode complementar outras formas de telecomunicação como o telefone ou a videoconferência. A interface também espacializa a telecomunicação, permitindo que os usuários transformem os espaços remotos sem estarem fisicamente presentes. Assim como um celular ligado no viva voz altera o aspecto sonoro de um ambiente remoto, a interface possibilita, por exemplo, modificar a iluminação, a configuração espacial ou a sensação térmica do ambiente.

Para facilitar a compreensão do funcionamento da interface, a explicação está dividida em cinco partes: (i) a estrutura de suporte, (ii) o hardware, (iii) o software, (iv) a interação básica e (v) outras interações possíveis.

A estrutura de suporte (i) foi construída utilizando tubos de PVC e peças de madeira para as bases e as articulações (Figura 1). As peças foram projetadas utilizando os softwares SketchUp e Rhinoceros e foram fabricadas no LAGEAR (Laboratório Gráfico para Experimentação Arquitetônica) utilizando a cortadora laser para cortar chapas de compensado de $10 \mathrm{~mm}$. Foram desenvolvidos diversos encaixes para conexão entre os tubos e dos tubos com as bases. A estrutura tem quatro bases sendo que três são dispostas formando um triângulo e uma é colocada no centro desse triângulo. Os tubos de PVC, conectados por peças de 
madeira, formam pernas articuladas que se apoiam sobre duas bases: a central e uma das bases externas. A base central é móvel e controlada por um robô que, ao se mover, altera a configuração espacial, abrindo e fechando as pernas. interface pois elimina a necessidade de configurar o port forwarding no modem ou no roteador.

A interação básica (iv) é a alteração da configuração espacial da estrutura a partir da apropriação dos usuários (Figura 3).

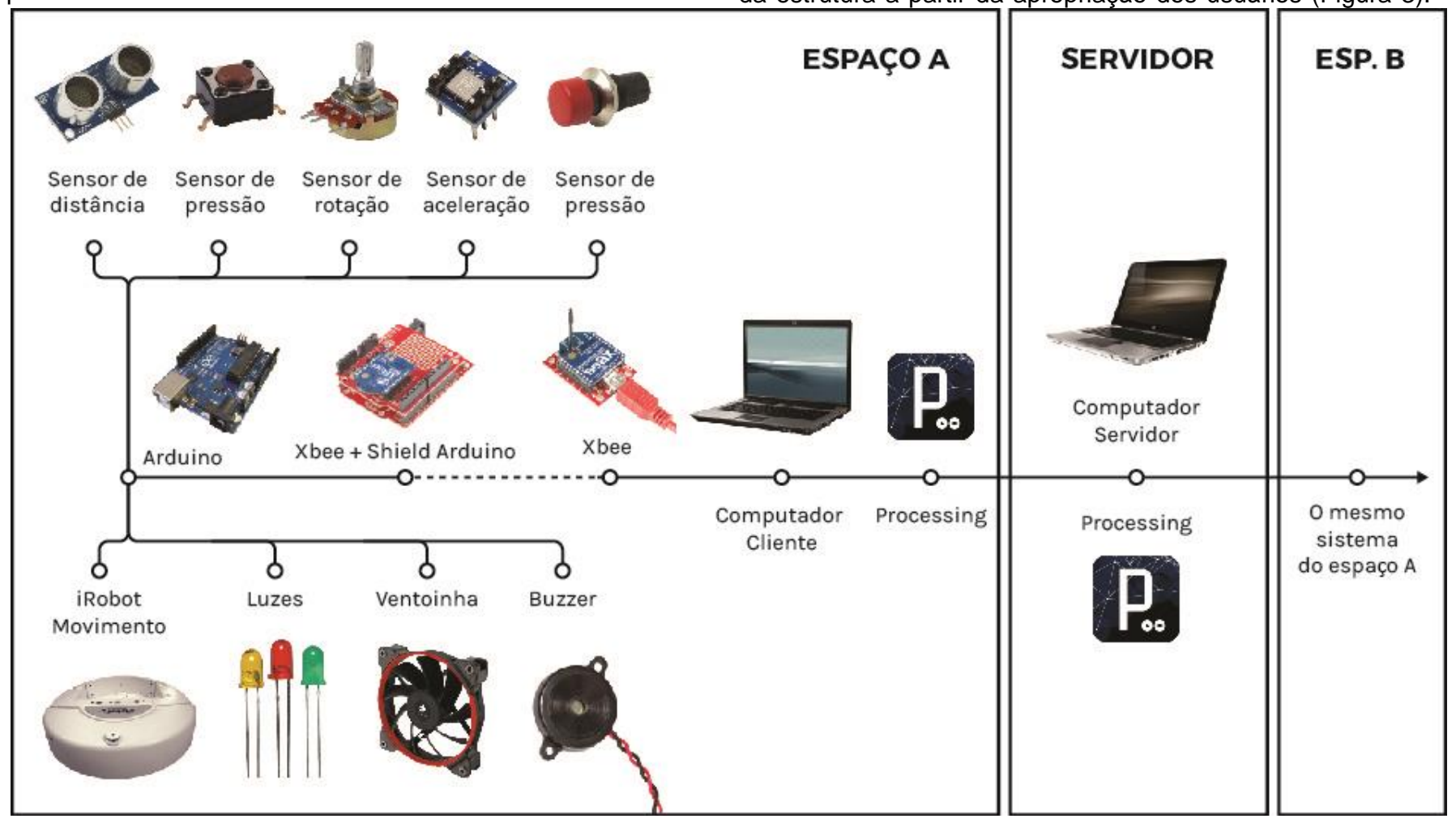

Figura 2: Esquema de comunicação e hardware necessário para conexão.

O hardware (ii) de cada estrutura é composto por um Arduino, um iRobot Create, dois XBees e um computador com acesso à internet. $\mathrm{O}$ iRobot Create é a base robótica que controla o movimento da base central. O robô é controlado por um microcontrolador Arduino, que se comunica com o computador por uma conexão sem fio utilizando um par de XBees que, por sua vez, envia os dados ao ambiente remoto por meio do software desenvolvido no Processing (Figura 2).

Esse software permite aos usuários conectarem até seis sensores analógicos, três sensores digitais, seis atuadores analógicos e três atuadores digitais. Os atuadores disponíveis são: ventoinhas, LEDs, motores DC, servo motores e motores vibradores. Os sensores disponíveis são: sensores de luz, movimento, presença, pressão, distância, temperatura, orientação (bússola) e rotação. Por meio da manipulação de conexões físicas os usuários podem recombinar os sensores e atuadores como desejarem.

O software (iii) desenvolvido no Processing contém duas partes, o servidor e o cliente. O servidor recebe os dados de todos os clientes e os distribui conforme a solicitação. Toda comunicação é feita utilizando o protocolo TCP (Transmission Control Protocol) por ser rápido o suficiente para uma comunicação em tempo real. Apesar de não ser essencial o uso de um servidor, ele facilita a instalação da
Há uma interface no espaço A e uma interface no espaço B. Ambas executam os mesmos movimentos. Quando o usuário A se aproxima da base central da interface $A$, um sensor de distância percebe sua presença e 0 robô se move, afastando-se do usuário. $A$ interface $B$ reproduz o mesmo movimento no ambiente $B$. Se o usuário $B$ se aproxima do centro da interface $B$, ambas as estruturas se movem, buscando um ponto médio entre o usuário $A$ e $\circ \mathrm{B}$. Essa movimentação possibilita a comunicação proxêmica, amplia a sensação de presença e estimula os usuários a negociarem a configuração do espaço.

Além da própria estrutura ser um atuador, ela também serve como suporte para outros sensores e atuadores, facilitando a espacialização da comunicação (v). Assim como esses sensores, outros objetos não eletrônicos podem ser acoplados para enriquecer a experiência da comunicação e aumentar o sentimento de pertencimento do usuário, estimulando um uso mais frequente da interface.

Duas estruturas foram construídas, instaladas e testadas em dois espaços da Escola de Arquitetura da UFMG. A comunicação entre sensores e atuadores foi possível utilizando o software desenvolvido e três computadores, sendo um deles um servidor, disponibilizado pelo LAGEAR, que acessa a internet utilizando um endereço de IP Fixo. 


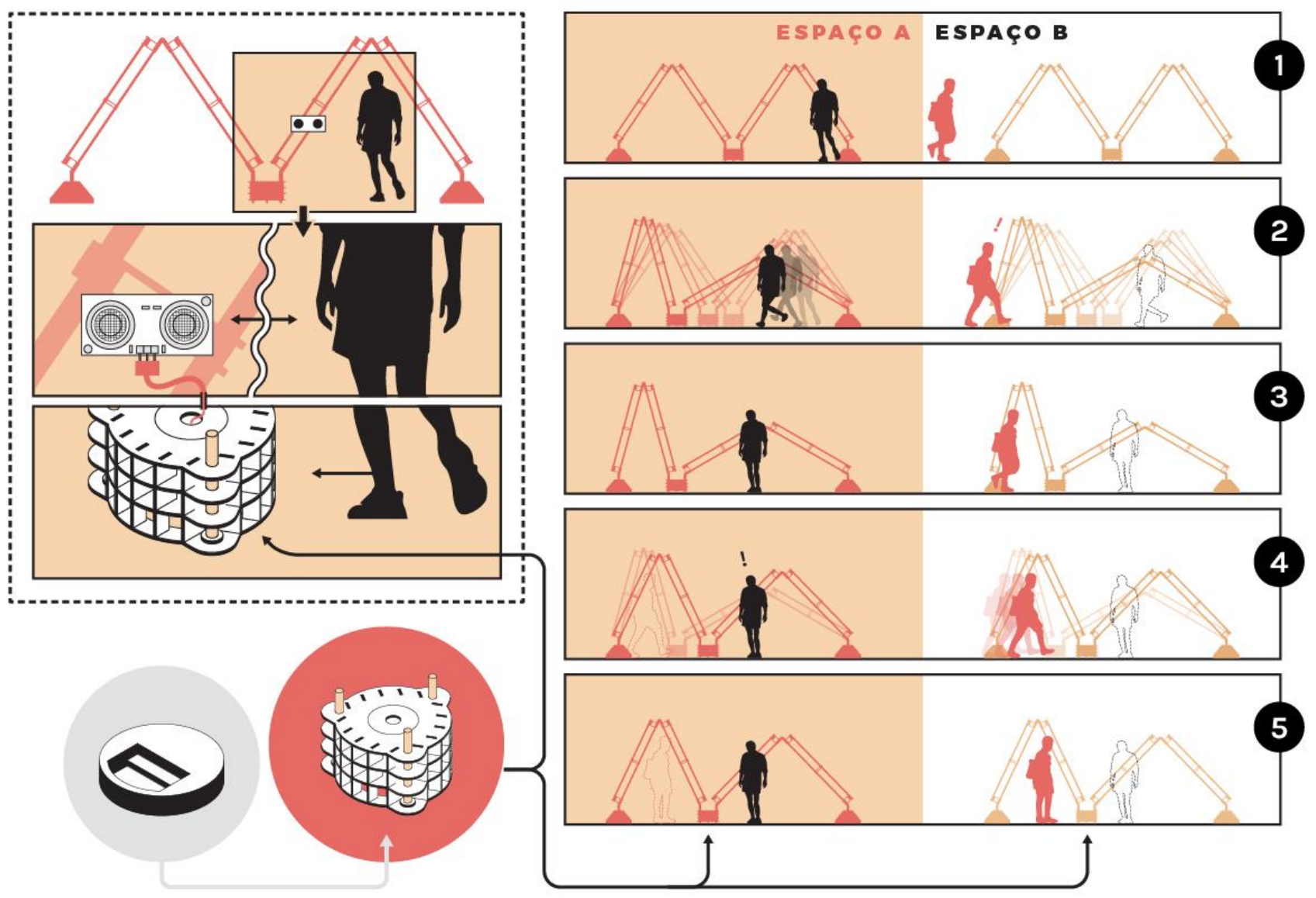

Figura 3: Esquema de movimentação do robô e interação dos participantes. (1) Ambas as estruturas em repouso. (2) $O$ robô sente a aproximação do usuário $A$ no ambiente $A$ e se move. A estrutura no ambiente $B$ reproduz o mesmo movimento chamando a atenção do usuário B. (3) O usuário $B$ se aproxima da estrutura no ambiente B. (4) A estrutura no ambiente B se movimenta em reposta à aproximação do usuário B. A estrutura no ambiente A também se move. (5) Ambas as estruturas param de se mover em uma posição média entre a distância dos dois usuários.

O programa desenvolvido conseguiu enviar os dados à uma taxa de atualização de $30 \mathrm{fps}$, adequada para uma comunicação em tempo real. Os sensores (potenciômetro, push-button e LDR) foram conectados diretamente (sem a mediação do servidor) aos atuadores (motores DC e LEDs) e acoplados à estrutura utilizando abraçadeiras de plástico. A estrutura apresentou instabilidade durante a movimentação do robô e a plataforma iRobot Create não tinha potência suficiente para movimentar as pernas articuladas em situações mais extremas (quando uma das pernas estava muito aberta).

\section{Conclusão}

A interface híbrida Trambolho, desenvolvida durante 0 Trabalho de Conclusão de Curso, teve sucesso ao criar uma forma de comunicação não-verbal em tempo real entre grupos remotos. Com ela foi possível espacializar a comunicação, provocando o engajamento corporal e uma maior sensação de presença, desenvolvendo um ambiente mais imersivo para a interação, ao invés de criar uma experiência contemplativa e visual. A interface apresentou alguns problemas como a instabilidade durante a movimentação que dificultou a realização de testes em ambientes menos controlados. Por isso não foi possível testar a criação de um ambiente para o diálogo horizontal nem mensurar a qualidade da comunicação em relação a outros dispositivos.

Possíveis avanços poderiam ser feitos ampliando a gama de sensores e atuadores usados e desenvolvendo um método para testar diferentes combinações, avaliando sua contribuição individual para a comunicação. Além disso, seria interessante desenvolver maneiras mais simples de acoplar os sensores a atuadores à interface e de recombiná-los por meio da manipulação física de plugs ou pela alteração de parâmetros na interface.

\section{Agradecimentos}

O autor gostaria de agradecer as agências de fomento FINEP, CAPES, CNPq, Fapemig, a Pró-Reitoria de PósGraduação da UFMG, a Pró-Reitoria de Graduação da UFMG, o grupo de pesquisa LAGEAR UFMG e a professora e pesquisadora Ana Paula Baltazar, que orientou o autor em seu trabalho de conclusão de curso e na produção deste artigo. 
SIGraDi 2016, XX Congress of the Iberoamerican Society of Digital Graphics 9-11, November, 2016 - Buenos Aires, Argentina 


\section{Referências}

Abreu, C. (2015). De Rolê. PISEAGRAMA: Passeio, (7), 32-37. Belo Horizonte.

Baltazar, A. P., Cabral Filho, J. S., Arruda, G., Melgaço, L., \& Almeira, M. (2014). Beyond the visual in urban interactive interfaces: dialogue and social transformation. International Journal of Creative Interfaces and Computer Graphics (IJCICG), 5(2), 1-15.

Barba, A. F. H., Cruz, E. E., Madrigal, J. L. G., \& Acosta, W. M. P. (2014). Estudio sobre el impacto de las TICs en la formación de capitales: El caso de Talea de Castro y Santa María Yaviche, Oaxaca. Lima: DIRSI publishes. Disponível em: $<$ http://dirsi.net/web/web_files/download/publicaciones/descargas MP-Estudio-sobre-el-impacto-de-las-TICs-en-la-formacion-decapitales-pdf-165.pdf>. Acesso em: 30 maio 2015.

Caldeira, T. P. R. (2014). Qual a novidade dos rolezinhos? Espaço público, desigualdade e mudança em São Paulo. Novos estudos - CEBRAP, São Paulo, (98), 13-20. Disponível em: <http://www.scielo.br/scielo.php? script=sci arttext\&pid=S0101$33002014000100002 \& \mid n g=p t \& n r m=i s o>$. Acesso em: 30 maio 2015.

Demo, P. (1998). Pobreza Política. Campinas: Autores Associados.

Foucault, M. (1987). Vigiar e Punir: Nascimento da prisão.Tradução: Raquel Ramalhete. Petrópolis: Vozes.

IBGE. (2015). Pesquisa nacional por amostra de domicílios: Acesso à Internet e à Televisão e Posse de Telefone Móvel Celular para Uso Pessoal. Rio de Janeiro. Disponível em: $<\mathrm{ftp}: / /$ ftp.ibge.gov.br/Acesso_a_internet

e_posse_celular/2013/pnad2013_tic.pdf>. Acesso em: 30 maio 2015.
Quintino, E., \& Baltazar, A. P. (2014). Interface para telecomunicação bidirecional não verbal em tempo real. Blucher Design Proceedings, 1(8), 231-235.

Lacerda, N., \& Bernardino, I. L.(2014). Fragmentação e integração nas metrópoles brasileiras: retorno à unidade espacial. In: Limonad, E., \& Castro, E. Um novo planejamento para um novo Brasil?. Rio de Janeiro: Letra Capital, 202-224.

Lansky, S. (2012) Na cidade, com crianças: uma etno-grafia espacializada. Tese (Doutorado em Arquitetura) - Escola de Arquitetura, Universidade Federal de Minas Gerais, Belo Horizonte.

Lefebvre, H. (2000) A produção do espaço. Tradução: Doralice Barros Pereira e Sérgio Martins. 269 p. Do original: La production de l'espace, 4e éd. Paris: Éditions Anthropos.

Lefebvre, H. (1976). The survival of capitalism: reproduction of the relations of production. Allison \& Busby.

Massey, D. (2006). Is the world really shrinking. Open University Lecture at the FACT Centre. BBC Radio, (3).

Teh, J. K. S., Cheok, A. D., Peiris, R. L., Choi, Y., Thuong, V., \& Lai, S. (2008). Huggy Pajama: a mobile parent and child hugging communication system. In: Proceedings of the 7th international conference on Interaction design and children, 250-257.

Visnjic, F. (2014). Di-Dah-Dit: A telepresence device by Camille Morizot. Disponível em: <http://www.creative applications.net/arduino- 2/di-dah-dit-a-telepresence-device-bycamille-morizot/>. Acesso em: 30 maio 2015.

Woods, L. (1996). The question of space. In: Aronowity, S. (Org.). Technoscience and cyberculture. London: Routledge, 279-292. 